Coordenadores:

Luciano Lourenço

Fátima Velez de Castro

Pluralidade na

Diversidade

de Riscos

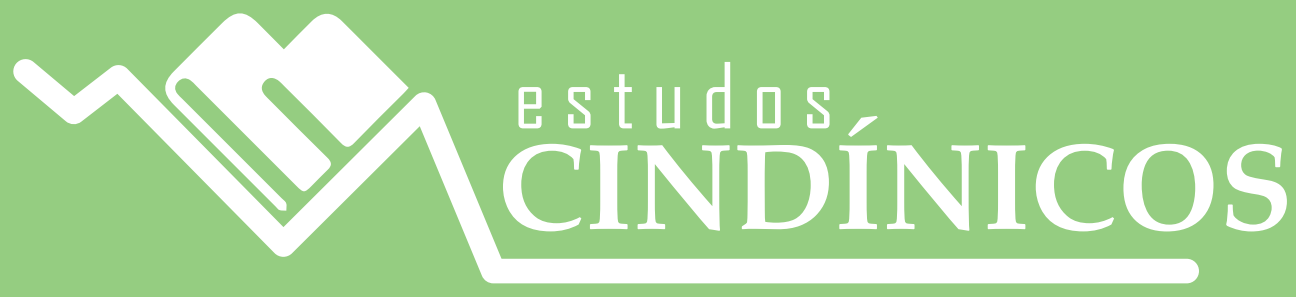

Riscos

Associação Portuguesa de Riscos, * Prevenção e Seguurança 
A "Pluralidade na diversidade de riscos" é uma obra composta por um conjunto de onze capítulos, cujos autores procuraram refletir aprofundadamente sobre uma multiplicidade de situações de risco, centradas na dimensão da avaliação, do aperfeiçoamento, da previsão e da mudança de paradigmas. Os trabalhos apresentados derivam da investigação científica realizada na área da formação, do clima e da sensação térmica, do ambiente e da psique. A partir da análise da diversidade fatual, pretende-se contribuir para aprimorar as respostas através da mitigação das falhas e de novas possíveis soluções.

É neste contexto territorial cada vez mais complexo, que urge olhar para a os riscos de forma plural e diversa, para que os estudos cindínicos possam manter o seu caráter inovador $\mathrm{e}$ utilitário, colocando-se ao serviço dos profissionais atuantes em momentos de risco, dos investigadores e, acima de tudo, das populações afetadas. 

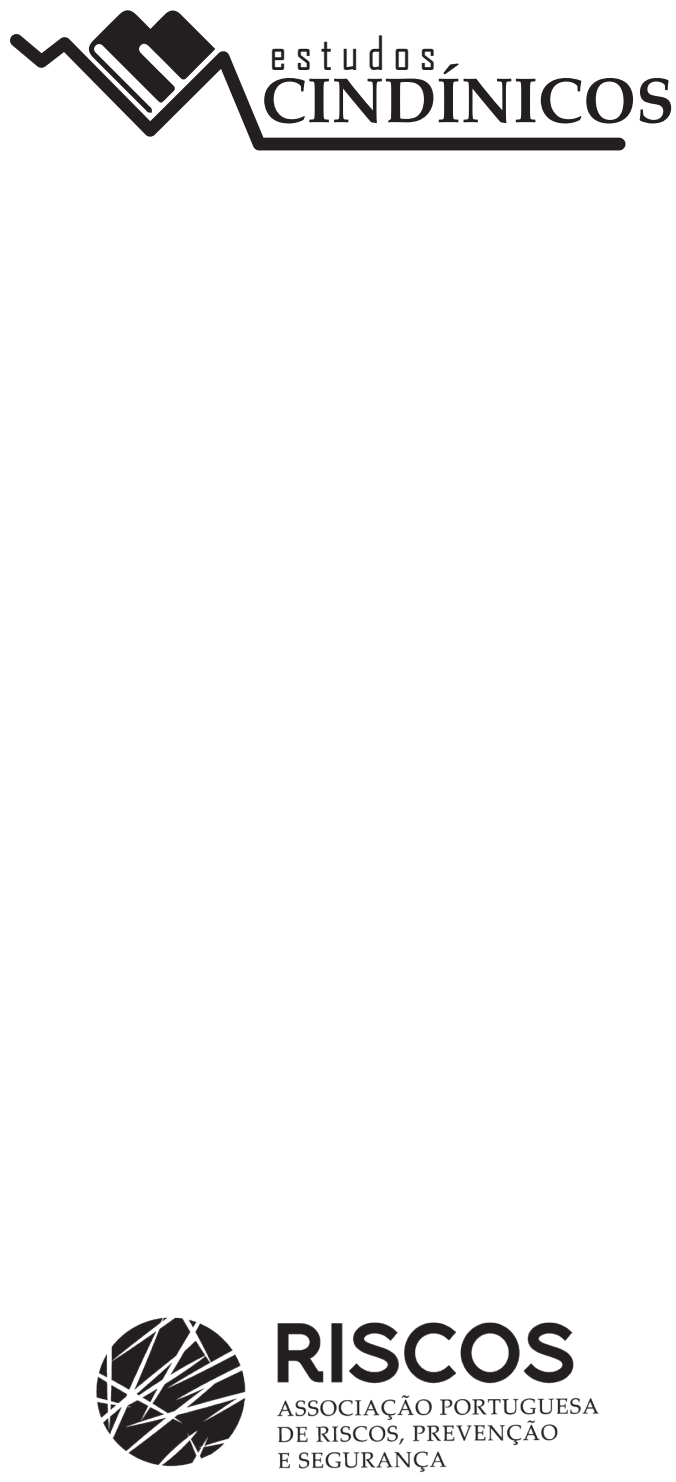


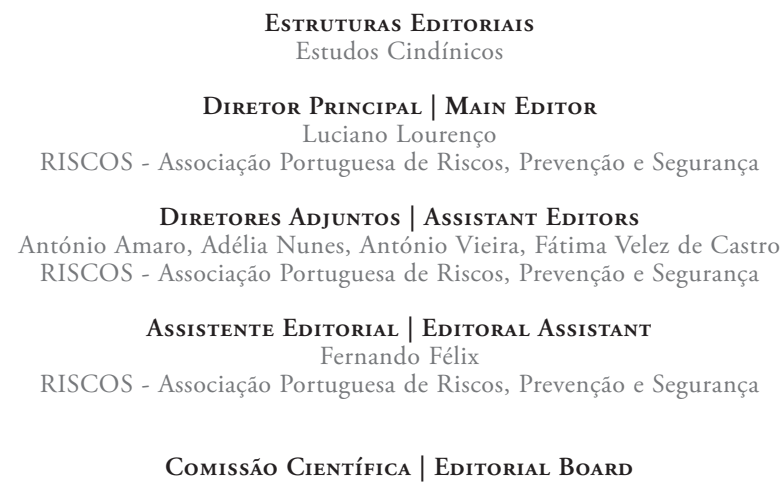

Ana Meira e Castro

Universidade do Porto

António Betâmio de Almeida

Instituto Superior Técnico, Lisboa

Cristina Queirós

Universidade do Porto

José Simão Antunes do Carmo

Universidade de Coimbra

Manuel João Ribeiro

Instituto Superior de Educaçáo e Ciências de Lisboa

Romero Bandeira

Instituto de Ciências Biomédicas Abel Salazar, Porto Universidade Distrital Francisco José de Caldas

Salvador Almeida

Universidade Lusófona do Porto
Carla Juscélia de Oliveira Souza

Universidade São Joâo del Rei

Maria Augusta Fernández Moreno

Católica do Equador

Miguel Castillo Soto

Universidade do Chile

Purificación Flaño

Universidade de La Rioja

Rita Cássia de Souza

Universidade Federal de Uberlândia

Yolanda Hernandez Peńa

Zeineddine Nouaceur

Universidade de Rouden

\section{Revisores Convidados | Invited Reviewers}

Adriana Panhol Bayma

Ministério do Meio Ambiente

António José Bento Gonçalves

Universidade do Minho

Eliana Marta Barbosa de Morais

Universidade Federal de Goiás

Helena Fernandez

Universidade do Algarve

Joáo Santos Baptista

Universidade do Porto

Lúcio Cunha

Universidade de Coimbra
Ney Roberto Váttimo Bruck

Universidade Federal de Pelotas

Roberto Lamberts

Universidade Federal de Santa Catarina

Rui Gama

Universidade de Coimbra

Teresa Durães Albuquerque

UInstituto Politécnico de Castelo Branco

Virgínia Maria Barata Teles

Universidade do Minho 
LUCIANO LOURENÇO

FÁTIMA VELEZ DE CASTRO

(COORDS.)

\section{PLURALIDADE NA DIVERSIDADE DE RISCOS}




\section{EDIÇÃo}

RISCOS - Associação Portuguesa de Riscos, Prevenção e Segurança

Email: riscos@riscos.pt

URL: https://www.riscos.pt/publicacoes/sec/

\section{Coordenaçáo Editorial}

Luciano Lourenço e Fátima Velez de Castro

\section{IMAGEM DA CAPA}

Karine Nieman

\section{Pré-IMPressáo}

Fernando Félix

\section{EXECUÇão GráficA}

Simôes \& Linhares, Lda.

ISSN

2184-5727

DOI (Série)

https://doi.org/10.34037/978-989-54295-1-6

\section{Depósito Legal \\ 449622/18}

ISBN

978-989-54295-5-4

ISBN Digital

978-989-54295-4-7

\section{DOI}

https://doi.org/10.34037/978-989-54295-4-7_5

\footnotetext{
${ }^{\circ}$ Dezembro 2018, RISCOS - Associação Portuguesa de Riscos, Prevenção e Segurança
} 


\section{SUMÁRIO}

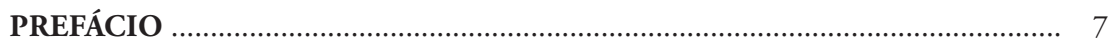

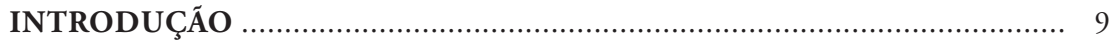

Avaliaçáo e adequação dos currículos de defesa civil dos cursos de formaçáo e aperfeiçoamento do corpo de bombeiros do rio de janeiro com vista à reduçáo do risco de desastres

Adriana Aparecida Bianchi Azevedo

O papel dos agrupamentos de corpos de bombeiros na mudança do paradigma da proteçáo civil municipal

Óscar Ferreira Catarino e António Duarte Amaro

Différences climatiques observées pour l'étude des précipitations et de la production de soja dans deux régions au Brésil

Vinicius Carmellos

Injustiça ambiental em um contexto industrial: Villa Hayes, Paraguai, como zona de sacrifício

Lidia Susana Tellez Ramos, Leo Name e Céline Veríssimo

Duas cançóes e o estresse pós-traumático

Altino Bessa Marques Filho e Victor Hugo Ferreira Silva

Como prever o isolamento térmico do vestuário para um ambiente térmico

Mário Talaia

As alteraçóes climáticas e a proteção civil

Nuno Gomes e Henrique Vicêncio

Bank erosion risks in Ouerrha catchment in northern Morocco: assessment and development issues

Mohammed El-fengour, Carlos Bateira, Abdelhak El-fengour, Abdelghani Houari and Mstafa Hmamouchi 


\section{SUMÁRIO}

Evoluçáo temporal (2009-2015) dos movimentos em massa na regiáo leste do estado de Sáo Paulo - Brasil

Geórgia Jorge Pellegrina, Anna Silvia Palcheco Peixoto e Ilza Machado Kaiser

As áreas de preservaçáo permanente e a sua importância na prevenção do risco (geomorfológico): estudo de caso em Santa Maria, RS, Brasil

Fernanda Maria Follmann, Franciele da Silva, Eliane Maria Foleto e Francisco

da Silva Costa

Riscos ambientais da exploração mineral na mina Pedra de Ferro-Caetité-BA

Altemar Amaral Rocha e Vaneusa Silva Pereira 


\section{PREFÁCIO}

Os riscos apresentam uma grande diversidade, quer nas causas que os podem originar, quer nas consequências que a sua manifestação pode determinar, pelo que só uma abordagem com pluralidade permite apresentar uma visão holística das múltiplas possibilidades de abordagem que os estudos dos riscos e das catástrofes proporcionam.

Ora, esta obra, em que são apresentadas várias perspetivas de análise, resulta precisamente de uma série de textos que, embora abordem temáticas diferentes, desde os riscos naturais aos antrópicos, e com estes materializados nos riscos tecnológicos e sociais, faz com que todos eles estejam ligados pelo mesmo fio condutor, que consiste em prevenir a sua manifestação, tomando as necessárias medidas de segurança, adequadas a cada tipo de risco, com o objetivo de reduzir os danos causados pelas suas manifestaçóes.

Mas, como todos sabemos, entre a teoria e a aplicação prática existe um longo caminho que é necessário ir percorrendo e a publicação deste volume constitui mais um pequeno passo, no sentido de divulgar situaçóes que poderiam ter sido evitadas ou, pelo menos, cujos efeitos poderiam ter sido bem mais reduzidos se houvesse uma melhor percepçáo do ricos e uma maior cultura de segurança.

Com efeito, o objetivo desta série é o de ir dando alguns pequenos passos, visando esse objetivo, através da edição regular de novas obras que, todos os anos, ajudem a alertar para situaçôes concretas de manifestaçôes de riscos.

Tendo em consideração que o ano de 2018 foi o de arranque desta nova coleção e que, com a publicação deste volume, foram dadas à estampa cinco obras, não podemos deixar de considerar que a série arrancou com fulgor e será desejável que, no próximo ano, possa manter o mesmo ritmo de publicação.

Para que isso aconteça e porque a série está aberta à colaboração de todos quantos se preocupam com os riscos e as suas manifestaçóes, sejam eles e elas associados ou náo da RISCOS, contamos receber propostas para publicar livros nesta série, de modo a que ela possa ser útil a todos quantos pretendem reduzir os efeitos das catástrofes.

Coimbra, 30 de novembro de 2018. 



\section{INTRO DUÇÃO}

Fátima Velez de Castro

Departamento Geografia e Turismo, CEGOT e RISCOS, Universidade de Coimbra (Portugal) ORCID: 0000-0003-3927-0748 velezcastro@fl.uc.pt

Fernando Rebelo (2010), numa das suas obras derradeiras, onde sistematizou o desenvolvimento da relação entre a Geografia Física e os Riscos Naturais ${ }^{1}$, ao invocar o contributo dos geógrafos percursores do estudo destes fenómenos em Portugal, deixou a seguinte reflexão:

"No entanto, se as observaçôes "em cima do acontecimento" foram importantes para muitos geógrafos, foi quase sempre através do estudo de situaçōes de crise acabadas de ocorrer que puderam deduzir como elas, frequentemente, resultavam da evolução de situações de perigo, que talvez pudessem ser evitadas" (Rebelo, 2010, p. 28).

Nesta obra intitulada "Pluralidade na diversidade de riscos", agrupa-se um conjunto de capítulos, derivados do esforço de investigação científica de vários autores que, na sua essência, expressam essa mesma preocupação, ou seja, a de refletir aprofundadamente sobre uma multiplicidade de situaçóes de risco, assim como as formas de mitigação. Tendo em conta as palavras componentes dos vários títulos enunciados, percebe-se a natureza do objetivo desta obra, centrada em quatro ações principais, a saber: avaliar, aperfeiçoar, mudar paradigmas, prever. No fundo, partir da diversidade fatual das causas das situaçóes, pretende-se refletir sobre as formas de aprimorar as respostas através da mitigação das falhas, assim como de novas possíveis soluções. É nesta lógica epistemológica que, por um lado, se poderão corroborar e aperfeiçoar paradigmas; por outro, repensá-los numa lógica de mudança e de inovação.

\footnotetext{
${ }^{1}$ Rebelo, F. (2010), Geografia Fisica e Riscos Naturais. Coimbra: Imprensa da Universidade de Coimbra.
} 
Os trabalhos aqui apresentados organizam-se em torno de quatro áreas temáticas, nomeadamente a formação; o clima e a sensação térmica; o ambiente; a psique.

No que diz respeito à formação, Adriana Azevedo apresenta um estudo em que pretende avaliar a adequação dos currículos de defesa civil para o corpo de bombeiros do rio de janeiro, tendo em vista a redução do risco de desastres. A sua pesquisa incidiu em cursos ministrados pela Escola Superior de Comando de Bombeiro Militar a na Academia de Bombeiro Militar D. Pedro II, através do levantamento das ementas, grade curricular e planos de sessão, sendo a metodologia utilizada de cariz empírico-analítico, com base na análise comparativa.

Já Óscar Catarino e António Amaro procuraram refletir sobre a mudança de paradigma da proteçáo civil municipal, tendo em conta o papel dos agrupamentos de corpos de bombeiros, no que diz respeito às respostas ao socorro dadas à população. Metodologicamente, os autores optaram pelo estudo de caso dos agrupamentos dos corpos de bombeiros de Mafra e Espinho, tendo sido realizadas entrevistas semiestruturadas, que serviram de base a uma análise de conteúdo.

Sobre a questão do clima e da sensação térmica, dois capítulos abordam áreas temáticas de interesse. Vinicius Carmellos compara a variabilidade das chuvas durante o cultivo da soja, tendo como referência o período temporal compreendido entre 1998-1999 e 2012-2013. A sua pesquisa centra-se na região noroeste do Rio Grande do Sul e na região Norte do Mato Grosso. O autor optou por uma abordagem estatística, analisando os dados mensais totais acumulados entre outubro e abril dos anos propostos, com posterior cálculo da correlação multivariada entre os fatores de precipitação, superfície cultivada e quantidade produzida.

Nuno Gomes e Henrique Vicêncio apresentam os resultados de um trabalho de investigação, cujo objetivo se centrou no estudo do grau de envolvimento dos municípios portugueses do continente, na problemática das alteraçóes climáticas, além de analisarem os modos de articulação com a administração central, em especial com os organismos responsáveis pela proteção civil. Os autores basearam os procedimentos metodológicos num questionário em plataforma virtual (Google), o qual foi respondido por 278 Câmaras Municipais.

No que concerne à dimensão da sensação térmica, Mário Talaia analisou o conforto térmico, tendo em conta as condiçóes termohigrométricas resgistadas em am- 
biente específico. Com base na validação de um método de cálculo de isolamento térmico de vestuário, o autor intersecciona fatores como a temperatura do ar, a temperatura do termómetro húmido, entre outros, para perceber o nível de conforto dos intervenientes, na relação entre o contexto de exposição e o vestuário usado.

No que diz respeito ao ambiente, Geórgia Pellegrina, Anna Peixoto e Machado Kaiser, realizaram uma evolução temporal dos movimentos de massa na região leste do estado de S.Paulo, no Brasil, no período temporal de 2009 a 2015. Os autores pretenderam averiguar a relaçáo entre a pluviosidade, a ocorrência de movimentos de massa, a densidade populacional e o número de indivíduos afetados. Do ponto de vista do método de trabalho, foram numeradas as ocorrências dos três períodos mais críticos do tempo em estudo, tendo sido a distribuiçẫo espacial das ocorrências e de suas vítimas comparadas com as precipitações normalizadas em função das normais pluviométricas e da densidade populacional dos municípios.

Já Fernanda Follmann, Franciele da Silva, Eliane Foleto e Francisco Costa, discutiram a importância das áreas de preservação permanente na prevenção do risco geomorfológico, na microbacia hidrográfica de Chácara das Flores, Em Santa Maria, Rio Grande do Sul, Brasil. O método utilizado permitiu combinar a cartografia da área em estudo com o mapa das áreas de risco geomorfológico.

Também Mohammed El-Fengour, Carlos Bateira, Abdelhak El-Fengour, Abdelghani Houari e Mstafa Hmamouchi apresentam um trabalho sobre os processos hidroerosivos nas Montanhas do Rif, em Marrocos, e de como este tipo de risco está a afetar as infraestruturas e territórios adjacentes (redes viárias, terrenos agrícolas, etc), com as consequências socio-económicas conexas. Para realização do estudo, os autores recorreram a fotografias aéreas, cartografia, assim como ao cálculo "cumulative rainfall'.

Valdemar Rocha e Vaneusa Pereira abordam o tema da exploração mineral no Maciço do Espinhaço, na Bahia, Brasil, dando conta dos riscos ambientais associados, assim como das alteraçôes sócio-espaciais decorrentes, nomeadamente no que respeita ao acesso aos recursos hídricos. A metodologia usada baseou-se na recolha de dados em contexto de trabalho de campo, pela observaçáo direta, assim como por captação de imagens fixas e realizaçáo de questionários por entrevista e por inquérito. 
Lídia Ramos, Leo Name e Céline Veríssimo dão visibilidade ao caso de Vila Hayes, no Paraguai, refletindo sobre as injustiças ambientais e de como estas mais afetam populaçôes vulneráveis, com fragilidades económicas e sociais. Os autores agruparam e discutiram um vasto conjunto de dados, reforçando o papel dos geógrafos enquanto ativistas e promotores da justiça social, dando voz à situação periclitante de comunidades de/em risco.

Por fim, a dimensão da psique está plasmada no capítulo de Altino Filho e Vitor Silva, que abordaram a questáo do transtorno de stress pós-traumático, enfatizando o papel da música como ferramenta que coloca em evidência as angústias e os traumas da sociedade moderna. Tendo como base duas letras de cançôes, os autores realizaram uma análise de conteúdo, procurando evidenciar o benefício desta arte como difusora da dinâmica patológica em causa e, em certa medida, desconstruir os estereótipos em torno dos transtornos mentais.

Num contexto territorial cada vez mais complexo, é urgente olhar para a os riscos de forma plural e diversa, para que os estudos cindínicos possam manter o seu caráter inovador e utilitário, colocando-se ao serviço dos profissionais atuantes em momentos de risco, dos investigadores e, acima de tudo, das populaçóes afetadas. 


\title{
AS ÁREAS DE PRESERVAÇÁO PERMANENTE E A SUA IMPORTÂNCIA NA PREVENÇÁO DO RISCO (GEOMORFOLÓGICO): ESTUDO DE CASO EM SANTA MARIA, RS, BRASIL
}

\author{
PERMANENT PRESERVATION AREAS AND THEIR \\ IMPORTANCE IN (GEOMORPHOLOGICAL) RISK \\ PREVENTION: CASE STUDY IN \\ SANTA MARIA, RS, BRAZIL
}

Fernanda Maria Follmann

Universidade Federal de Santa Maria/bolsista Capes/PDSE (Brasil) ORCID:0000-0002-3877-4621_ferfollmann@yahoo.com.br

Franciele da Silva

Universidade Federal de Santa Maria/bolsista Capes/PDSE (Brasil) ORCID:0000-0003-2853-7187_francieli17@gmail.com

francieli17@gmail.com
Eliane Maria Foleto
$\begin{array}{r}\text { Departamento de Geociências, Universidade Federal de Santa Maria (Brasil) } \\ \text { efoleto@gmail.com }\end{array}$
Francisco da Silva Costa
Departamento de Geografia, Universidade do Minho (Portugal)

Resumo: O trabalho tem como objetivo discutir a importância das Áreas de Preservação Permanente (APPs) na prevenção do risco geomorfológico, na área de estudo da microbacia hidrográfica Chácara das Flores, em Santa Maria/RS/Brasil. Para isso, combinou-se o mapa de ocupaçáo em área de APP com o mapa das áreas de risco geomorfológico. Como metodologia, se utilizou o que está disposto em E. Oliveira et al., 2004. 
Como resultado, obteve-se $81 \%$ das áreas de risco coincidindo com as áreas que estão ocupadas nas APP, demonstrando assim a necessidade da efetivação da legislação ambiental em relação a ocupação nestes espaços.

Palavras-chave: Áreas de preservação permanente, incompatibilidade legal, risco geomorfológico, Santa Maria.

Abstract: The objective of this work is to discuss the importance of Permanent
Preservation Areas (APPs) in the prevention of geomorphological risk.
A case study of the Chacara das Flores hydrographic basin, in Santa
Maria/RS/Brazil was used for this. The occupation map in an APP
area was combined with the map of geomorphological risk areas. The
methodology used is that described in E. Oliveira et. al., 2004. It
was found that $81 \%$ of the risk areas coincided with the areas that
are occupied in the APPs, thus demonstrating the need to enforce
environmental legislation in relation to the occupation in these spaces.

Keywords: Permanent preservation areas, legal incompatibility, geomorphological risk, Santa Maria.

\section{Introdução}

A intensificação dos processos de urbanização e industrialização aliados ao aumento populacional promovem maiores impactos no sistema natural. Essa situaçấo se torna mais sensível quando vinculada diretamente às áreas urbanas onde a concentraçấo populacional e a demanda por infraestrutura são crescentes. Na maioria dos casos, sobretudo nos países em desenvolvimento como o Brasil, a expansão urbana ocorre de modo desordenado, sem planejamento, desencadeando conflitos ambientais e situações de desequilíbrio entre o meio natural e a ocupaçáo humana, principalmente no que tange a ocupação inadequada em áreas como as Áreas de Preservação Permanente (APP). 
Por estarem associadas a importantes funçóes ambientais como "preservar os recursos hídricos, a paisagem, a estabilidade geológica, a biodiversidade, o fluxo gênico de fauna e flora, proteger o solo e assegurar o bem-estar das populaçóes humanas" (Brasil, 2012) as Áreas de Preservação Permanente (APPs), regulamentadas pelo Código Florestal, possuem uso restrito, cabendo ao Poder Público assegurar a sua manutenção e segurança. No entanto, a legislação ambiental vigente sobre a restrição de ocupação das APPs não é respeitada na sua totalidade, o uso restrito dessas áreas acaba sendo negligenciado pela população, a qual se utiliza de áreas demasiadamente próximas de rios, nascentes e encostas para fins de moradia, configurando assim, um cenário de incompatibilidade com a legislação, cenário esse definido como de Incompatibilidade Legal.

As áreas de preservação permanente (APP) são espaços especialmente protegidos, tratados como instrumento legal pela Política Nacional do Meio Ambiente na promoção da sustentabilidade ambiental. A preservação dessas áreas é fundamental para a conservação do equilíbrio ecológico dos cursos d'água e para a manutenção da quantidade e qualidade dos recursos hídricos.

De acordo com o Código Florestal Brasileiro (Brasil, 2012) considera-se Área de Preservação Permanente, área protegida, coberta ou não por vegetação nativa, com a função ambiental de "preservar os recursos hidricos, a paisagem, a estabilidade geológica e a biodiversidade, facilitar o fluxo gênico de fauna e flora, proteger o solo e assegurar o bem-estar das populaçóes humanas". Assim, a lei considera as APPs, em relação as faixas marginais de qualquer curso d'água natural perene e intermitente, excluídos os efêmeros; as áreas no entorno das nascentes e dos olhos d'água perenes e as encostas ou partes destas com declividade superior a $45^{\circ}$, equivalente a $100 \%$ (cem por cento) na linha de maior declive.

Nesta perspectiva, as APPs são áreas protegidas que exercem fundamental importância na manutenção da vegetação, as quais exercem funçóes ambientais de relevada importância, pois mantêm o sistema em harmonia, a partir do qual asseguram o bem-estar das populaçóes.

As APPs, desse modo, desempenham diversos serviços ambientais, diretos ou indiretos. Integram processos como "a fotossintese, a ciclagem das águas, a conservação dos solos, a polinização, o controle de pragas, a competição entre organismos e a 
predação" (N. Bensusan, 2008, p. 25) e, agrega-se a estes, a prevenção ao risco, pois, ao manterem a estabilidade do ambiente, minimizam o risco ambiental.

Em relação ao risco, R. Julião et al. (2009) definem como a probabilidade de ocorrência de um processo e a respectiva estimativa das suas consequências sobre pessoas, bens ou ambiente, expressas em danos corporais e/ou prejuízos materiais e funcionais, diretos ou indiretos. C. Egler (1996) e C. Amaral (1998) consideram a classe maior do conceito de risco sendo representada pelo risco ambiental.

C. Egler (1996) associa assim, o risco natural ao comportamento dos sistemas naturais. Associação entre os eventos que ocorrem naturalmente, e que devido à ocupaçáo inadequada de certos espaços acarreta em riscos a população. $\mathrm{O}$ autor considera o grau de estabilidade e de instabilidade expresso em determinada área a eventos como inundaçóes, movimentos de massa e aceleração de processos erosivos, eventos estes que foram analisados na área da microbacia hidrográfica Chácara das Flores. Tornando, deste modo, a denominação de risco natural a que mais se adéqua a abordagem do trabalho. Associado a essa situação de desequilíbrios e conflitos ambientais está, na maioria dos casos, parte da sociedade que não dispóem de meios suficientes para obter um lugar seguro para sobreviver na cidade, deste modo, vê-se obrigada a residir em áreas como as de Preservação Permanente e/ou áreas naturalmente frágeis, como planícies de inundação, áreas deprimidas e vertentes íngremes, acarretando em possíveis situaçóes de risco para a população.

Perante a importância das Áreas de Preservação Permanente, tem-se como objetivo desta pesquisa analisar as funçóes ambientais das APPs, dentre estas, a de prevenção ao risco geomorfológico na microbacia hidrográfica Chácara das Flores, em Santa Maria/RS/Brasil.

Para tanto, é apresentado o estudo de caso da microbacia hidrográfica Chácara das Flores (fig. 1) situada nos bairros Chácara das Flores e Nossa Senhora do Perpétuo Socorro, em Santa Maria/RS. A escolha da área foi motivada pela importância que as APPs de drenagem e de encostas possuem nessa bacia, pois um estudo feito por E. Oliveira (2004) identificou dentro da bacia hidrográfica do Arroio Cadena a área da microbacia Chácara das Flores como uma área de médio e alto grau de risco geomorfológico, considerando como risco a dinâmica das vertentes - erosão e os movimentos de massa - e a dinâmica fluvial - processos de erosão das margens e de inundação. 


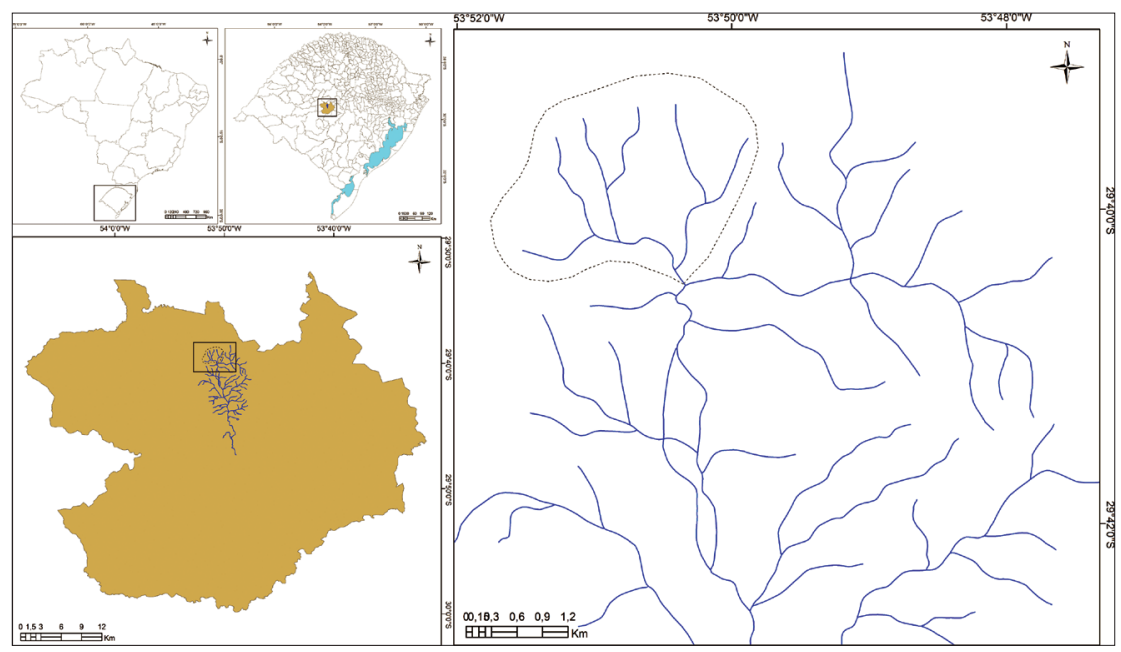

Fig. 1 - Localização da Microbacia Hidrográfica Chácara das Flores em relação à Bacia Hidrográfica do Arroio Cadena.

Fig. 1 - Location of the Chácara das Flores watershed in relation to the Arroio Cadena river basin.

Apesar disso, essas áreas nem sempre são preservadas, o que ocorre muitas vezes é o desmatamento destes locais para seu uso na agricultura, pecuária e uso urbano. Isso gera uma série de consequências, pois a cobertura natural dessas áreas iria atenuar o efeito erosivo, de lixiviação dos solos e, principalmente na regularização do fluxo hídrico (T. Costa et al., 1996).

O desmatamento das APPs, conhecidas também como matas ciliares, resulta na intensificação do assoreamento dos rios. Isso porque sem ela a erosão das margens leva sedimentos para dentro do rio, podendo inclusive mudar o curso do corpo d'água. Além disso, o processo de erosão se torna acentuado com a ocorrência de enchentes nas épocas de chuva. Dessa forma, as APPs têm um papel fundamental para impedir a erosão e assoreamento dos rios e garantir a manutenção das condiçôes básicas dos solos e das águas.

Além disso, as matas ciliares funcionam também como filtros, retendo defensivos agrícolas, poluentes e sedimentos que seriam transportados para os cursos drágua, afetando diretamente a quantidade e a qualidade da água e consequentemente a fauna aquática e a população humana (D. Quintas; R. Stolf; J. Casagrande, 
2007). São importantes também como corredores ecológicos, ligando fragmentos florestais e, portanto, facilitando o deslocamento da fauna e o fluxo gênico entre as populações de espécies animais e vegetais. Logo, a composição da vegetação ciliar exerce influência direta sobre os efeitos por ela proporcionados. Quanto maior a diversificação maior será a contribuição ao meio ambiente.

A conversão de áreas de floresta, cujos usos são limitados, em campo, agricultura, uso social e demais atividades antrópicas é um fenômeno que coloca em risco as funçôes ambientais das áreas com limitaçóes de uso, portanto caracterizam pontos de conflito. Estas áreas caracterizadas como conflito de uso do solo estão "entre as maiores responsáveis pelas erosóes, assoreamentos de rios, de barragens e de açudes, enchentes e efeitos das secas" (J. Rocha, 1997, p. 72), configurando-se assim, os riscos naturais.

Nesse contexto, destaca-se a área de estudo desta pesquisa, que se caracteriza por uma biodiversidade associada ao contato de duas unidades geomorfológicas (Depressão periférica Sul-Riograndense e Planalto Meridional brasileiro) e por ser uma área de nascentes de água. Esta biodiversidade caracteriza-se por pertencer ao Bioma Mata Atlântica, floresta que proporciona distintos serviços ecossistêmicos à sociedade de Santa Maria e demais seres vivos.

Um dos serviços ecossistêmicos proporcionados se refere a manutenção do fluxo hídrico, pois possibilita a infiltração da água, diminuindo o escoamento superficial, as inundaçôes e, com isso o risco associado. Para tanto, a vegetaçáo de Mata Atlântica existente nas Áreas de Preservação Permanente (APPs), contribuem efetivamente na minimização dos processos que geram o risco geomorfológico, pois realizam os processos mencionados em prol da manutenção dos serviços ambientais.

Com a manutenção dessas condiçôes básicas, mantem-se também o risco ambiental minimizado, pois os sistemas ambientais se encontram na sua organização natural. No entanto, as ocupaçóes das margens dos rios, caracterizadas no Brasil como APPs, alteram-se com a alteraçáo dos usos do solo e inserção de áreas impermeáveis, gerando áreas de risco. Em Santa Maria, nomeadamente na área de estudo, verifica-se a ocupaçáo de áreas associas ao risco, as mesmas, em grande se encontram também em Áreas de Preservação Permanente, intensificando o risco para a populaçấo. 
As alteraçóes no uso do solo nas encostas influenciam os processos erosivos que podem promover a alteração da dinâmica fluvial como, por exemplo, o desmatamento ou o crescimento de área urbana nas encostas, que reduz a capacidade de infiltração e aumenta o escoamento superficial, promovendo a erosão hídrica das encostas e fornecendo maior volume de sedimentos para a calha fluvial, o que resulta no assoreamento do leito e aumento da área inundada em períodos de precipitação (S. Cunha e A. Guerra, 1996). Desse modo, os processos de dinâmica superficial do relevo, quando se desenvolvem em ambientes onde a ação humana se encontra presente, podem ocasionar grandes perdas econômicas como também vitimar as populaçốes envolvidas.

Perante os possíveis cenários de riscos geomorfológicos e o contexto de conflitos ambientais descritos nas Áreas de Preservação Permanente, tem-se como objetivo desta pesquisa mapear e analisar as áreas de risco geomorfológico situadas em Áreas de Preservação Permanente da microbacia hidrográfica Chácara das Flores, Santa Maria/RS/Brasil, partindo da hipótese de que, se o Código Florestal fosse realmente efetivado, através de fiscalização e políticas públicas de controle dessas áreas, situaçôes de riscos à população poderiam ser evitadas e/ou mitigadas.

\section{Metodologia}

Para que o objetivo de mapear e analisar as áreas de risco geomorfológico situadas em Áreas de Preservação Permanente da microbacia hidrográfica Chácara das Flores fosse contemplado, o desenvolvimento de mapeamentos prévios foi necessário. Assim, para a elaboração do mapa de ocupação em APP foram combinados o mapa das Áreas de Preservação Permanente com o mapa de ocupação do solo da microbacia hidrográfica Chácara das Flores.

As APPs consideradas foram aquelas determinadas no Código Florestal, Lei n. ${ }^{\circ}$ 12.651/2012:

- $\quad-30$ metros para os cursos d'água de menos de 10 metros de largura;

- Raio mínimo de 50 metros no entorno de nascentes e olhos d'água perenes;

- Encostas ou partes destas com declive superior a $45^{\circ}$, equivalente a $100 \%$ na linha de maior declive. 
Para a identificação das áreas de risco geomorfológico foi realizada uma combinação dos mapas de susceptibilidade natural, padrão função urbana e eventos/ acidentes, como sugere C. Egler (1996).

As áreas naturalmente susceptíveis a risco foram estabelecidas considerando a rede de drenagem, o substrato geológico e as declividades da microbacia. Deste modo, são consideradas susceptíveis as áreas ocupadas que, segundo C. Egler (1996):

- Tenham declividade inferior a $2 \%$ e se localizem nas margens dos cursos d'água;

- Apresentam declividades superiores a $12 \%$, onde os processos erosivos das vertentes são mais acentuados;

- Depósitos fluviais juntos a rede de drenagem, determinados como geotecnicamente instáveis (Maciel Filho, 1990);

- Áreas onde foram evidenciados processos de dinâmica superficial em estágio intensificado pelas atividades antrópicas. Essas áreas foram identificadas em campo, coletadas as coordenadas geográficas de cada local, e marcados os pontos no mapa de susceptibilidade natural.

Para a confecção do mapa do padrão função urbana foram consideradas, como propóem E. Oliveira et al. (2004), as características construtivas/estruturais das moradias (padrão construtivo alto/médio/baixo), as condições de infraestrutura básica oferecidas à população residente no local, bem como a forma de ocupação do espaço (organizada/desorganizada). Portanto, o padrão urbano de determinada área expressa à vulnerabilidade do sistema social que em face de deflagração de um evento, pode vir a causar perdas econômicas e até mesmo humanas. A partir destes levantamentos pode-se estabelecer o padrão função urbana dividindo-se em Alto, Médio e Baixo padrão. Para a hierarquização foram atribuídos valores de 0 e 1 , conforme citam E. Oliveira et al. (2004), para os parâmetros considerados de acordo com sua ocorrência, como pode ser observado no QUADRo I.

A partir da soma atribuída às características que apresentam os locais pode-se estabelecer o padrão urbano, dividindo-se a área em: Alto Padrão Função Urbana (valor máximo 6 na soma total dos atributos); Médio (soma igual a 3, 4 e 5) e Baixo Padrão Função Urbana (soma igual a 0,1 e 2). 
QUADRO I - Parâmetros utilizados para a definição do Padrão Função Urbana.

TABLE I - Parameters used to define the urban function pattern.

\begin{tabular}{|l|l|l|}
\hline \multicolumn{1}{|c|}{ Variável } & \multicolumn{1}{c|}{ Característica } & Valor \\
\hline \multirow{2}{*}{ Malha Viária } & Pavimentada & 1 \\
\cline { 2 - 3 } & Não Pavimentada & 0 \\
\hline \multirow{2}{*}{ Esgoto } & Canalizado & 1 \\
\cline { 2 - 3 } & Direto no Ambiente & 0 \\
\hline \multirow{3}{*}{ Rede Pluvial } & Apresenta & 1 \\
\cline { 2 - 3 } & Não Apresenta & 0 \\
\hline \multirow{2}{*}{ Ocupação } & Alto/Médio & 1 \\
\cline { 2 - 3 } & Baixo & 0 \\
\hline \multirow{2}{*}{ Obras de Constrenção } & Organizada & 1 \\
\cline { 2 - 3 } & Desordenada & 0 \\
\cline { 2 - 3 } & Apresenta & 1 \\
\hline & Não Apresenta & 0 \\
\hline
\end{tabular}

Fonte/Source: E. Oliveira et. al., 2004.

Já o registro de acidente é utilizado na hierarquização do risco como um fator agravante da situação de risco já instalada. A coleta de dados foi obtida através dos órgãos públicos responsáveis, Defesa Civil e Corpo de Bombeiros, pesquisa em acervos de jornais, além da entrevista com os moradores das áreas de risco, onde se identificaram os eventos/acidentes relacionados aos processos de risco à inundação, movimentos de massa e erosão das margens.

O grau de risco é o produto do cruzamento entre a susceptibilidade natural, o padrão função urbana e a ocorrência de algum evento/acidente na área, conforme o QUADRO II.

QUADRO II - Cruzamento das variáveis e respectivos graus de risco.

TABLE II - Intersection of variables and respective degrees of risk.

\begin{tabular}{|l|l|l|l|}
\hline Padráo Urbano & Alto & Médio & Baixo \\
\hline Susceptibilidade Natural & Risco Baixo & Risco Moderado & Risco Alto \\
\hline Ocorrência de Eventos/Acidentes & Risco Moderado & Risco Alto & Risco Iminente \\
\hline
\end{tabular}


Desta forma foi possível estabelecer quatro graus para as áreas de risco:

- "Risco IV (cinza): Quando a área ocupada com Alto Padrão apresenta susceptibilidade natural e não tem registro de ocorrência de eventos, constitui-se em uma área de grau IV, considerada de baixo risco;

- Risco III (amarelo): Ocorre quando a área apresenta-se com susceptibilidade natural e está ocupada com moradias de Médio Padrão Urbano sem ocorrência de eventos. Ou se a área susceptivel estiver ocupada por moradias de Alto Padrão Urbano com registro de ocorrências. Assim, constituem as áreas de risco moderado de grau III;

- Rico II (laranja): Quando a área susceptivel apresentar predominio de ocupação de Médio Padrão Urbano com registro de eventos, ou de Baixo Padrão Urbano sem registro de evento, constitui-se em áreas de alto risco de grau II;

- Risco I (vermelho): Quando a área ocupada com moradias de Baixo Padrão Urbano apresentar susceptibilidade natural e ocorrência de eventos é considerada de risco iminente, recebendo grau I, onde a intervenção dos órgãos públicos responsáveis deve ser de curto prazo" (E. Oliveira et al., 2004).

De posse dessa hierarquização foi elaborado o mapa das áreas de risco geomorfológico, espacializando, assim, os diferentes graus de risco atribuídos à área da microbacia hidrográfica Chácara das Flores. Na fig. 2 pode-se observar, de forma completa, a combinaçáo de mapas que possibilitaram o resultado final da pesquisa:

A partir dos mapeamentos foi possível realizar a discussão sobre a importância das APPs em relaçấo à proteção ao risco às populaçôes. Isso porque muitas áreas de risco têm como característica a ocupação urbana, potencializando o risco já pré-existente.

As APPs são áreas de proteção devido aos serviços ambientais que as suas características proporcionam, sendo um destes a minimizaçáo do risco às populaçóes. Verificou-se, desse modo, a necessidade de efetivação da legislação ambiental na Microbacia Chácara das Flores, pois a ocupação urbana existente nestas áreas, além de incompatível em termos legais é, também um fator intensificador do risco ambiental.

Exemplo dessa afirmação pode ser observado nas catástrofes que atingiram a regiáo serrana do Rio de Janeiro/Brasil, em 2011, e a regiáo do Vale do Itajaí, em Santa Catarina/Brasil, no ano de 2008. Os dois eventos contabilizaram centenas de vítimas fatais, além de prejuízos econômicos decorrentes ou potencializados pela 


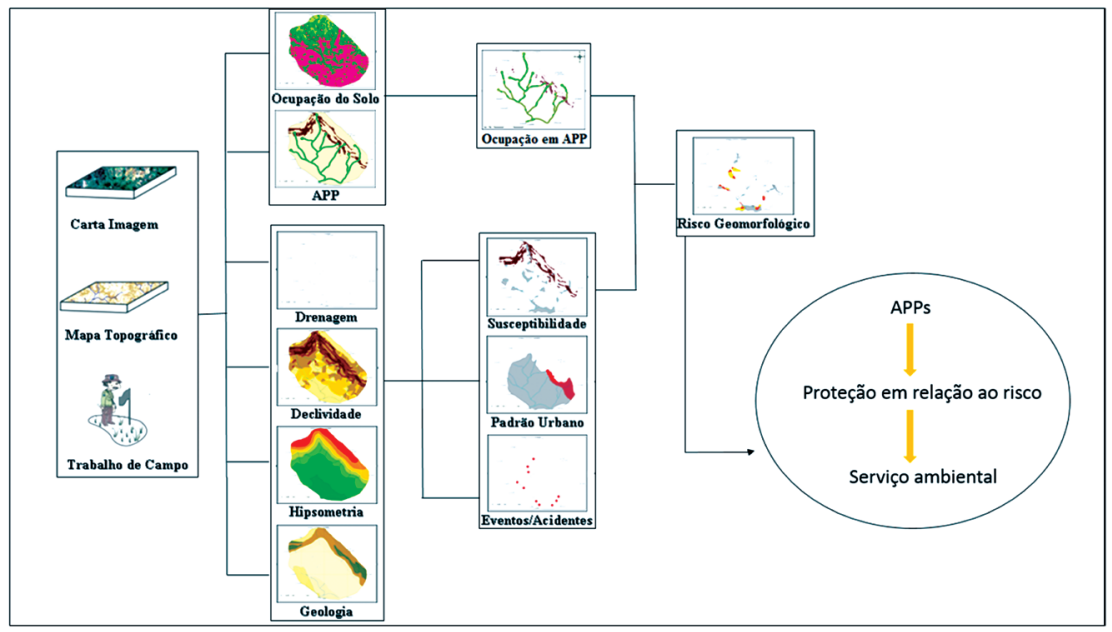

Fig. 2 - Organização estrutural dos mapeamentos e análise das informaçôes.

Fig. 2 - Structural organization of mapping and information analysis).

ocupação em Áreas de Preservação Permanente com fins agrícolas, com a presença de edificaçóes ou obras de infraestrutura, como estradas.

\section{Resultados e discussóes}

Com base no que foi observado nos trabalhos de campo, fica evidente no decorrer da microbacia, um cenário de incompatibilidade com a legislação ambiental. Podem-se perceber ao longo da área, intervençóes na rede de drenagem, como a proteção das margens com pedras soltas e pneus, além da canalização em alguns pontos e barramentos no decorrer do canal principal. $\mathrm{Na}$ área da microbacia fica evidente, ainda, o descaso com os resíduos sólidos, que têm como destino final os canais de drenagem.

Quanto às Áreas de Preservação Permanente ocupadas com uso do solo urbano, identificou-se um total de 73,27 \% da área total das APPs ocupadas irregularmente (fig. 3). Destacando-se, principalmente, a ocupação urbana em áreas de margens da rede de drenagem. 


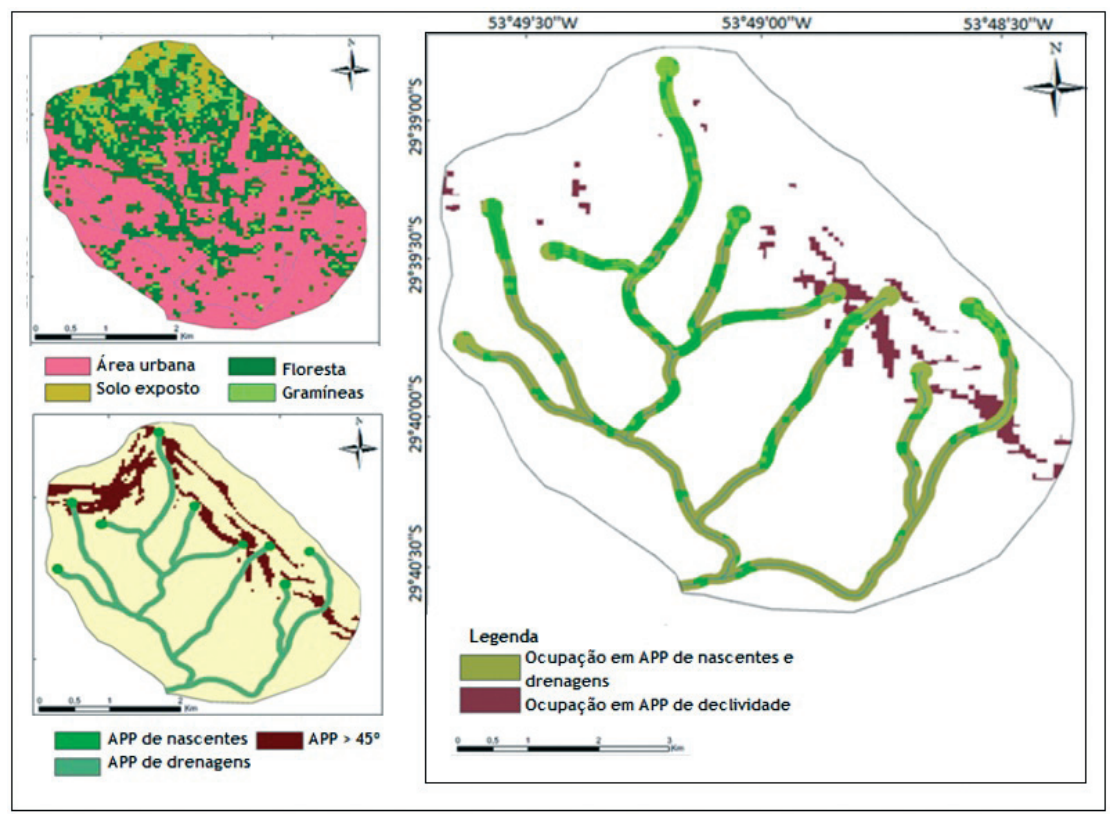

Fig. 3 - Ocupação urbana em área de APP.

Fig. 3 - Urban occupation in APP area.

Em vista das declividades acentuadas, as quais dificultam a instalação de moradias, as APPs das nascentes e encostas estão em melhores condições de conservação, embora a expansão urbana já avance em direção a essas áreas. Algumas nascentes já se encontram degradadas em alguns pontos, mas ainda prevalece a legislação.

Quanto à identificação das áreas de risco geomorfológico na microbacia hidrográfica Chácara das Flores, pode-se concluir que predominam as áreas condicionadas à dinâmica fluvial (Dfluv) e em menor proporção à dinâmica das vertentes (Dve e Dvm) (fig. 4).

$\mathrm{Na}$ área da microbacia, as áreas de risco associadas aos processos erosivos estão localizadas em setores onde a declividade é maior, na porção norte e leste da microbacia. Essas áreas apresentam um bom suporte de infraestrutura, tanto pública quanto das residências, viabilizando assim uma maior segurança no local. Todavia, o alto padrão urbano não exclui o risco, apenas o torna menos possível. Nessas áreas náo foram identificados registros de acidentes, todavia a susceptibilidade ocorre, caracterizando áreas de grau de risco IV. 


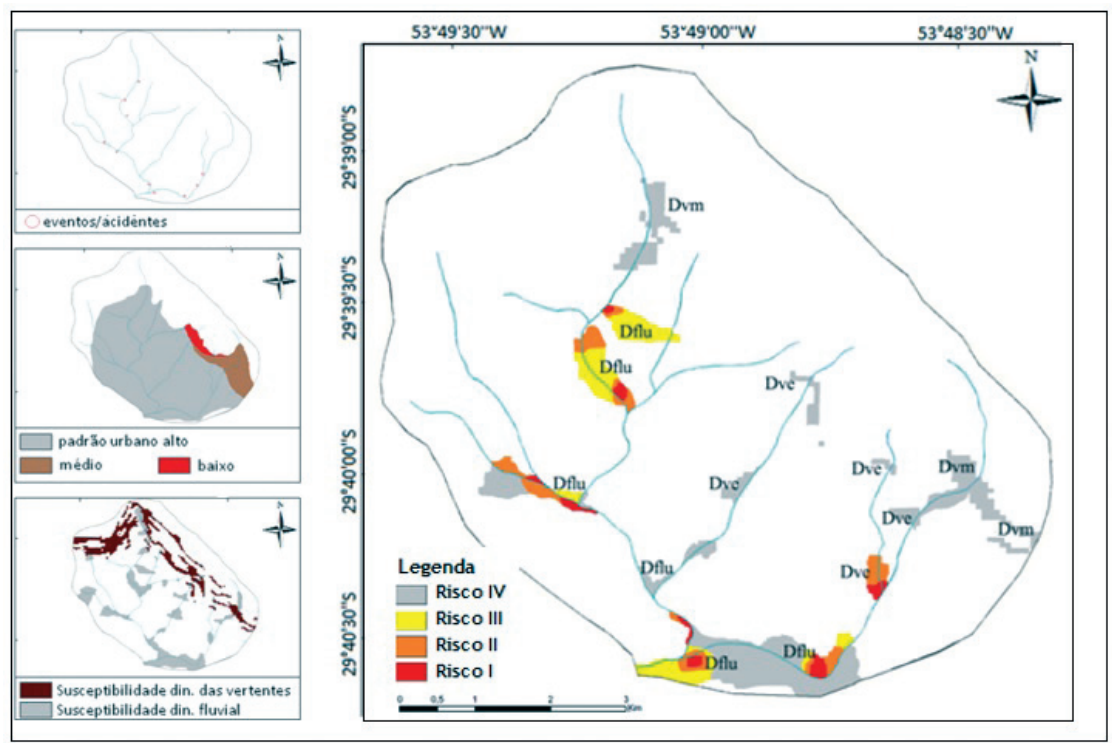

Fig. 4 - Áreas de risco geomorfológico na microbacia Chácara das Flores.

Fig. 4 - Geomorphological risk areas in the Chácara das Flores watershed.

Já os movimentos de massa são processos evidenciados com menor amplitude dentro da área da microbacia, ficando restritos às áreas com maior declividade e, ainda, sem adensamentos populacionais.

As áreas de risco associadas à dinâmica fluvial, em sua maioria, localizam-se na confluência dos canais que formam a microbacia (fot. 1). São comuns os eventos que causam inundaçóes nesses locais, atingindo as residências demasiado próximas às confluências e, estas por apresentarem um baixo padrão urbano, assim como localizarem-se em área susceptível e onde já foram registrados eventos/acidentes, fazem com que estas áreas possuam risco iminente face aos processos da dinâmica fluvial, notadamente às inundaçōes.

Os outros pontos de risco identificados referentes à dinâmica fluvial estão associados à baixa capacidade de drenagem dos depósitos aluviais que formam as áreas de margem dos canais, além destas circunstâncias de risco, tem-se um forte processo de erosão, o que já acarretou a destruiçáo de residências localizadas nessas áreas, segundo relato do Corpo de Bombeiros. Essas áreas também foram classificadas como sendo 
de risco iminente face aos processos geomorfológicos evidenciados no local, pois se tem uma classe de baixo padrão urbano associado às características naturais propícias a desencadear circunstâncias de risco, além do registro de eventos/acidentes.

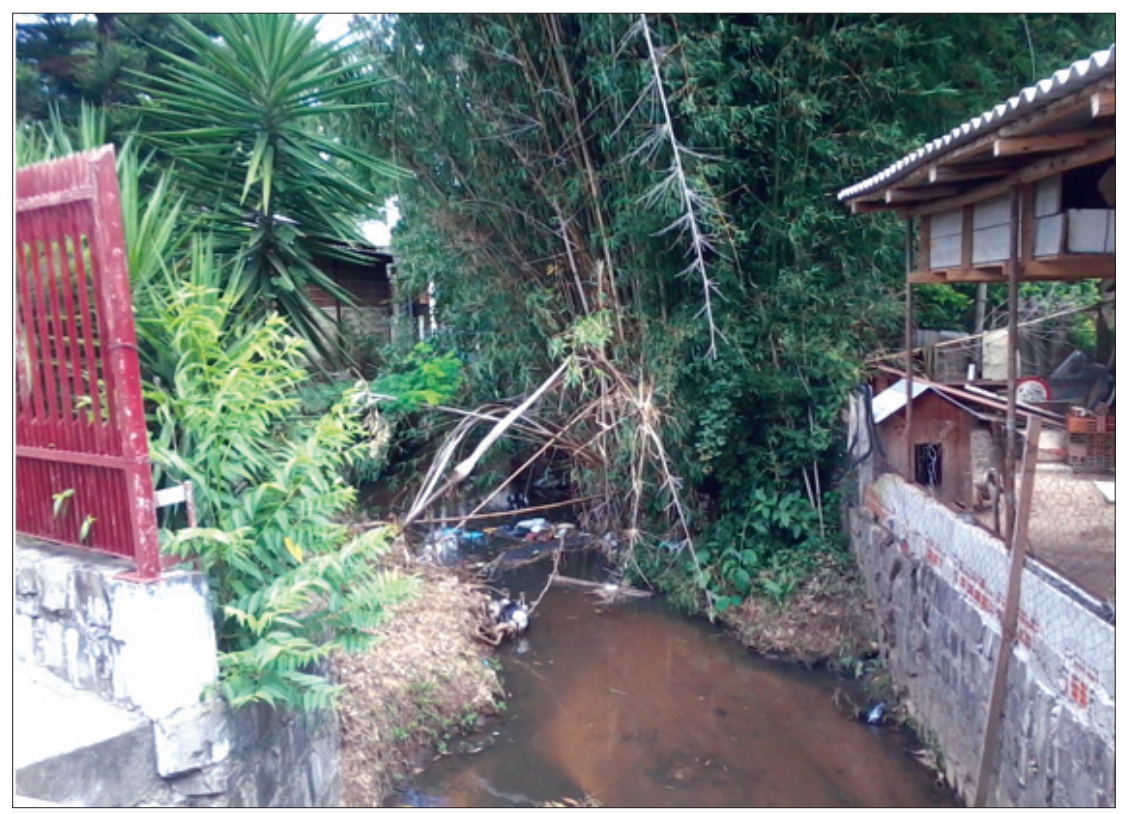

Fot. 1 - Área de risco geomorfológico sujeita a inundação na confluência de dois canais da microbacia hidrográfica.

Photo 1 - Geomorphological risk area subject to flooding at the confluence of two channels of the watershed

Ainda é possível identificar alteraçóes na rede de drenagem, como canalização de nascentes, impermeabilização do leito e margens dos canais de drenagem. Outro agravante dos processos de dinâmica fluvial a destacar são as ruas e travessas não pavimentadas que, na maioria das vezes, terminam junto ao canal principal, colaborando com o deposito de sedimentos na rede de drenagem.

Através do mapeamento das áreas de risco geomorfológico na microbacia, pode-se quantificar que 18 \% da área total da microbacia estão em situação de risco. A espacialização desses locais é dispersa e com predomínio de áreas com risco a processos de dinâmica fluvial. 
Analisando os resultados obtidos por meio dos mapeamentos da ocupação urbana em APP e das áreas consideradas de risco geomorfológico na microbacia de estudo, pode-se afirmar que as de ocupação urbana são, de fato, coincidentes com as áreas de risco geomorfológico. Isso porque, dos $18 \%$ das áreas de risco identificadas, $13 \%$ encontram-se situadas em Áreas de Preservação Permanente (fig. 5).

Como se pode observar, as duas condicionantes se sobrepóem em maior proporção ao longo das áreas de margens. As áreas de nascentes e as encostas com declividades superiores a $45^{\circ}$ náo apresentam valores expressivos, pois são áreas que ainda passam por um processo de expansão urbana, não havendo a presença de muitas edificaçôes. O que faz da área motivo de alerta, uma vez que a tendência é que se repita o cenário das áreas mais rebaixadas se ocorrer a intensificação da urbanização.

Com os resultados do estudo de caso da microbacia hidrográfica Chácara das Flores é possível afirmar que a necessidade de efetivação da legislação brasileira sobre proteção das APPs é necessária, não somente para proteger a biodiversidade e qualidade dos recursos hídricos, mas também proteger as populaçôes em relação ao

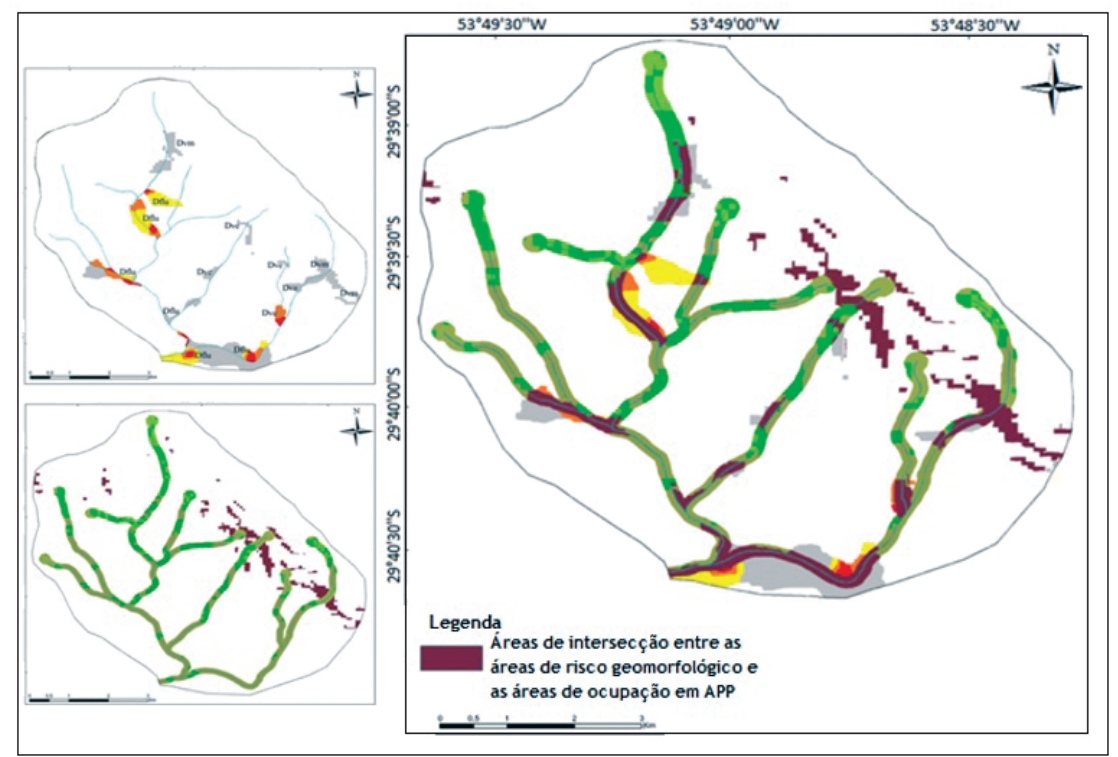

Fig. 5 - Associação das áreas de ocupação urbana com as áreas de risco.

Fig. 5 - Association of urban occupation areas with risk areas. 
aumento do risco. Desse modo, os serviços ambientais prestados pela manutenção das Áreas de Preservaçấo Permanente, de acordo com o disposto nas leis ambientais vão além do contributo ambiental, mas também social.

\section{Conclusão}

Através do estudo de caso da microbacia hidrográfica Chácara das Flores pode-se considerar alguns fatores que condicionam esse cenário: as áreas de ocupaçáo em APP podem ser consideradas um espaço de transição entre o técnico, o político e o educacional. O fato das Áreas de Preservação Permanente apresentarem ocupação, de algum modo, consolida o estudo técnico, que atribui riscos a essas áreas, mas também configura uma deficiência na fiscalização, atribuída ao poder público, e, muitas vezes, uma falta de conhecimento da população, oriundo da ausência de uma educação ambiental adequada no conjunto da sociedade.

Ainda é possível concluir que existe a necessidade de adequação da atual legislaçáo protetora, sobretudo com uma fiscalizaçáo eficaz e com políticas públicas de controle e realocação de populações que habitam as APPs, principalmente naquelas áreas que o risco se apresenta de forma mais intensa.

Destaca-se, ainda, que medidas preventivas, de controle ou de mitigação de eventos de riscos são menos onerosas e mais eficientes na prevençáo de tragédias. Embora inevitáveis esses eventos são previsíveis. Nesse contexto, a maior conscientização e responsabilidade da população e dos poderes públicos se mostram como medida de adaptação inadiável. 


\section{Referências Bibliográficas}

Amaral, C. P. (1988). Mapeamento Geológico-Geotécnico da Baixada de Sepetiba e Maciços Circunvizinhos - Parte Sul da Folha de Santa Cruz (Dissertação de Mestrado em Geografia). Instituto de Geociências, Universidade Federal do Rio de Janeiro, Rio de Janeiro, pag. 130.

Bensusan, N. (2008). Seria melhor ladrilhar? Biodiversidade: como, para que e por quê. 2 ed. São Paulo: Editora Universidade de Brasília.

BRASIL. Lei n. 12.651, de 25 de maio de 2012. Dispóe sobre a proteção da vegetação nativa; altera as Leis n. 9.393, de 19 de dezembro de 1996, e 11.428, de 22 de dezembro de 2006; revoga as Leis $n$. 4.771, de 15 de setembro de 1965, e 7.754, de 14 de abril de 1989, e a Medida Provisória n. 2.166-67, de 24 de agosto de 2001; Diário Oficial [da República Federativa do Brasil], Brasília, DF. Disponível em: http://www.planalto.gov.br/ccivil_03/_ato2011-2014/2012/lei/112651.htm. Acesso em: 14 ago. 2012.

Costa, T. C. C., SouzA, M. G., Brites, R. S. (1996). Delimitação e caracterização de áreas de preservaçáo permanente por meio de um Sistema de Informaçōes Geográficas (SIG). Revista Árvore, Viçosa MG, v.20, n.1, p. 129 - 135, abril.

Cunha, S. B. e Guerra, A. J. T. (1996). Degradação Ambiental. In: Guerra, A. J. T. e Cunha, S. B. (Orgs.). Geomorfologia e Meio Ambiente. Rio de Janeiro: Bertrand Brasil.

Egler, C. A. G. (1996). Risco Ambiental como critério de Gestáo do Território: uma aplicaçâa à zona costeira brasileira. Território, Rio de Janeiro, v. 1, n.1, p. 31-41, jul./dez.

Juliăo, R. P., NerY, F., Ribeiro, J. L., Branco, M. C., Zêzere, J. L. (2009). Guia Metodológico para a Produçâo de Cartografia Municipal de Risco e para Criação de Sistemas de Informação Geográfica (SIG) de base municipal. Porto/Portugal: Autoridade Nacional de Proteção Civil.

Oliveira, E. L. A. (2004). Áreas de risco geomorfológico na Bacia do Arroio Cadena, Santa Marial RS: zoneamento e hierarquização (Dissertação de Mestrado em Geociências). Universidade Federal do Rio Grande do Sul, Porto Alegre, pag. 147.

Quintas, D. A. C., Stolf, R., Casagrande, J. C. (2007). Recuperação de matas ciliares na micro bacia do Ribeirão das Furnas no Município de Araras - SP. In: IV Congressp de Pósgraduação, São Carlos - SP. Anais de Eventos da UFSCar, v. 3, p. 1235.

Rebelo, F. (2003). Riscos Naturais e Acção Antrópica. Coimbra: Imprensa da Universidade.

Rocha, J. S. M. (1997). Manual de projetos ambientais. Santa Maria: Imprensa Universitária. 



\section{CONLUSÃO}

Fátima Velez de Castro

Departamento Geografia e Turismo, CEGOT e RISCOS, Universidade de Coimbra (Portugal) ORCID: 0000-0003-3927-0748 velezcastro@fl.uc.pt

Revisitando aqueles que foram os resultados dos trabalhos de investigação apresentados na obra "Pluralidade na diversidade dos riscos", pode-se concluir que os investigadores e os profissionais ligados à área dos riscos, estão cada vez mais conscientes para a crescente complexidade dos territórios, tanto do ponto de vista físico, como do ponto de vista humano. Já Luciano Lourenço (2015), na senda da discussão sobre a dimensão do pragmatismo e do risco ${ }^{1}$, referia:

"Por isso, se, como parece, o objetivo de muitos estudos for a mitigação do risco, então teremos de ser pragmáticos e considerar não só a fase da pré-catástrofe (...) que naturalmente deverá ser de preparaçāo, prevenção e previsão, mas também deverá ser tido em linha de conta o "durante", correspondente à fase de socorro (...) [e] a fase de pós-catástrofe, durante a qual será necessário reconstruir a área afetada" (Lourenço, 2015, p. 5).

No fundo, a multiplicidade de situaçóes quotidianas, leva a que de devam reequacionar procedimentos, assim como restruturar cenários de atuação. Um dos campos a repensar será o da dimensão formativa, com a atualização dos conteúdos e da prática letiva, assim como da cooperação entre entidades ligadas aos riscos e à proteção civil, no sentido de congregar esforços e criar sinergias, que permitam respostas mais rápidas e eficazes.

Além disso, é fundamental estar alerta e alertar para as alteraçóes ambientais. Nesta obra, chama-se a atenção para o fato de, por exemplo, as alteraçóes dos níveis de pluviosidade em determinadas regióes, poderem contribuir para significativas

\footnotetext{
${ }^{1}$ Lourenço, L. (2015). Risco, perigo e crise: pragmatismo e contextualização. In Siqueira, A., Valêncio, N., Siena, M. e Malagoli, M.A., Riscos de desastres relacionados à água. São Paulo: RiMa Editora.
} 
alteraçôes dos sistemas económicos e produtivos, criando fragilidades sociais tendencialmente estruturais. Por outro lado, é necessário alertar os governos locais para situaçôes de perigosidade ligadas a fenómenos excepcionai de diferente escala de afetação, quer no que diz respeito aos de rápida atuação (exemplo de precipitação intensa), como os de lenta progressáo (por exemplo, o caso dos períodos de seca). Neste contexto, também é necessário alertar para a dimensão do ordenamento do território, e da forma como a construçáo habitacional e funcional pode gerar situaçôes de perigo iminente em situação de risco natural.

Chamar a atenção para estas e outras situaçóes, parece ser uma preocupação constante em todos os estudos apresentados nesta obra e, em geral, para toda a comunidade académica. Comunicar ciência, transpor o fosso que muitas vezes existe entre os cientistas e a comunidade civil, transferir o conhecimento, nem sempre é uma tarefa fácil e óbvia. Mas é necessária e cada vez mais urgente, para que os estudos científicos possam ser de/sobre/para a sociedade.

Nesta lógica, sugere-se uma possibilidade de comunicação através da música, seja como mecanismo de catarse para os afetados (por exemplo, por stress pós-traumático), seja por canal de divulgação de práticas e de comportamentos a adotar (por exemplo, em campanhas de prevenção). Além disso, o contexto escolar educativo, também virá reforçar esta perspetiva através da psicoeducação, educando e difundindo conhecimento para a população escolar e para a sociedade em geral.

Mas haverá mais para fazer no campo dos riscos. Esperamos, pois, que os estudos cindínicos possam vir a ganhar um destaque cada vez mais evidente no quotidiano, continuando sempre na senda da prevenção, mitigaçẫo e promoção da segurança e do bem-estar das populaçōes, sobretudo dos mais vulneráveis. 


\section{SÉRIE \\ ESTUDOS CINDÍNICOS}

Títulos Publicados:

1 Incêndios em Estruturas. Aprender com o Passado;

2 Educação para a Redução dos Riscos;

3 Metodologia de Análise de Riscos através de Estudos de Casos;

4 Riscos Hidrometeorológicos;

5 Pluralidade na Diversidade de Riscos;

Tomos em preparação:

6 Risco Sísmico - Aprender com o Passado;

7 Geografia dos Incêndios Florestais. 50 anos de Incêndios a queimar Portugal;

8 Efeitos dos Incêndios Florestais nos Solos de Portugal;

9 Floresta, Incêndios e Educação;

10 Redução do Risco e Educação. 


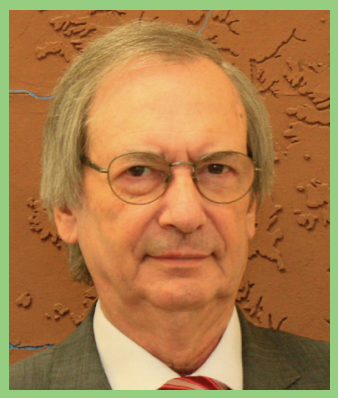

Luciano Lourenço é doutorado em Geografia Física, pela Universidade de Coimbra, onde é Professor Catedrático.

É Diretor do NICIF - Núcleo de Investigação Científica de Incêndios Florestais, da Faculdade de Letras da Universidade de Coimbra e Presidente da Direção da RISCOS - Associação Portuguesa de Riscos, Prevenção e Segurança.

Exerceu funções de Diretor-Geral da Agência para a Prevenção de Incêndios Florestais, Presidente do Conselho Geral da Escola Nacional de Bombeiros e Presidente da Direção da Escola Nacional de Bombeiros.

Consultor científico de vários organismos e de diversas revistas científicas, nacionais e estrangeiras, coordenou diversos projetos de investigação científica, nacionais e internacionais, e publicou mais de mais de três centenas de títulos, entre livros e capítulos de livro, artigos em revistas e atas de colóquios, nacionais e internacionais.

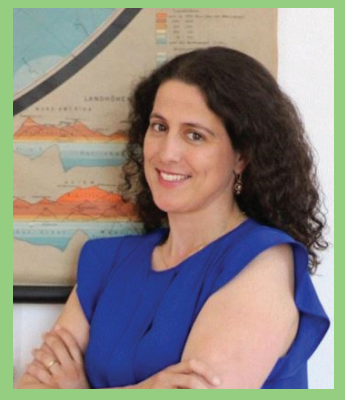

Fátima Velez de Castro é licenciada em Geografia (especialização em ensino), mestre em Estudos sobre a Europa e doutora em Geografia.

É Coordenadora do Mestrado em Ensino da Geografia no $3^{\circ}$ Ciclo e Ensino Secundário (FLUC); Coordenadora do Conselho de Formação de Professores da mesma instituição; membro da Comissão Científica do Departamento de Geografia e Turismo da Faculdade de Letras da Universidade de Coimbra; membro integrado do CEGOT (Centro de Estudos de Geografia e Ordenamento do Território).

É Tesoureira da RISCOS - Associação Portuguesa de Riscos, Prevenção e Segurança.

Foi Sub-Diretora do Curso de $10^{\circ}$ Ciclo (Licenciatura) em Geografia; membro do Conselho Pedagógico da Faculdade de Letras da Universidade de Coimbra; coordenadora geral da Mobilidade da mesma instituição.

Tem cinco livros publicados (três da sua autoria e dois em co-autoria) e cerca de sessenta outras publicações (capítulos de livros, artigos científicos em revistas nacionais e internacionais, artigos em atas de congressos, etc.). 


\section{RISCOS \\ ASSOCIAÇÃO PORTUGUESA DE RISCOS, PREVENÇÃO \\ E SEGURANÇA}

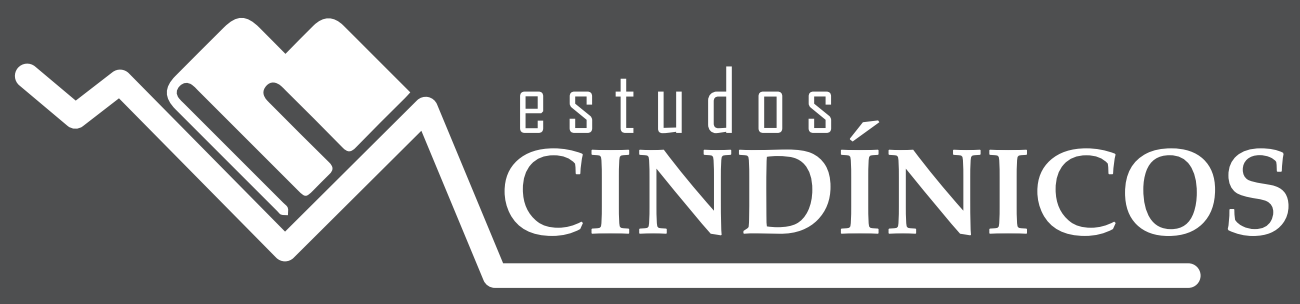

